\title{
HOW TO CHANGE THE TRAVELLERS" MOBILITY BEHAVIOURS? - EXAMPLES OF MOBILITY PLANS
}

The paper presents a mobility management concept as well as gives examples of mobility plans which are fundamental instruments of mobility management. A mobility plan includes activities for the promotion of sustainable mobility modes: bikes, public transport, walking trips and new means of private car usage (carpooling, carsharing systems). It also consists of solutions which realize an idea of sustainable transportation. Mobility plan activities allow to fulfill travellers' mobility needs and shape their mobility behaviours.

Keywords: mobility management, mobility plan, reduction of traffic congestion, travel behaviours.

\section{Introduction}

Nowadays cities are affected by an increasing number of cars Car traffic leads to considerable problems related with congestion, parking, accidents as well as environmental pollution. Thus a very important issue is the change of the people's mobility behaviours towards more sustainable transport means: public transport, bikes, walking trips or shared car usage - carpooling and carsharing systems.

We can shape travellers' attitudes and behaviours using the mobility management concept. Mobility management is an approach to the passenger transport, oriented on promotion of the sustainable mobility modes and on management of the demand for car usage [1].

Change of mobility attitudes and behaviours is a very long and not easy process. There is a necessity to take into consideration specific needs and expectations of different users. That is why the mobility management concept consists of a range of services and instruments corresponding to individual clients' needs that can be flexibly adapted to various conditions and expectations of target groups. The core of mobility management is made by "soft" measures like:

- Information and consulting (providing travelers with information about sustainable mobility modes, analyzing the present transport situation, looking for solutions, evaluating alternatives and recommendation of the best solution, e.g. comparison of travel time and costs of different transport modes).

- Transport services and products (this category includes not only the standard services and products as tickets, maps with city transport network but also innovative services and products: loyalty programs, public transport tickets which provide entrance to cultural or sports events etc.).
- Products sale and reservation, e.g. sale of the public transport tickets or rail ticket reservation in the area of the institution.

- Organization and coordination of services and solutions (e.g. organization of the carpooling or carsharing systems in institutions, coordination of mobility services for the handicaps).

- Educational and marketing activities (sustainable mobility trainings, seminars, happenings, marketing campaigns etc.).

"Soft" measures usually enhance the effectiveness of the "hard" measures related with transport infrastructure development (e.g. new tram lines or new bike paths construction). Activities within mobility management "soft" measures do not require large financial investments - in comparison to the "hard" measures.

\section{Mobility plan - fundamental instrument of mobility management}

The fundamental instrument of the mobility management concept is a mobility plan (also: travel plan, trip reduction plan, green commuter plan, mobility actions, and mobility programme). The mobility plan integrates the above mentioned "soft' measures in one package of the activities. The mobility plan includes strategies for promotion of the idea of sustainable mobility and also consists of solutions and measures which realize the idea of sustainable mobility (in this case "to realize the idea of sustainable mobility" means: to create good conditions for trips made by sustainable mobility means") [2].

General aims of the mobility plans can be defined as:

- Change of travel behaviours of target groups towards pro - ecological transport modes (public transport, bikes, walking trips, new forms of private car usage - carpooling, carsharing systems).

* Katarzyna Nosal

Chair of Transport Systems, Faculty of Civil Engineering, Cracow University of Technology, Krakow, Poland, E-mail: nosal@transys.wil.pk.edu.pl 
- Improvement in accessibility to the institutions or to the areas.

- Reduction of parking needs.

- Reduction of traffic congestion.

Mobility plans are implemented for these places which generate and attract large traffic flows as e.g.: distinguished city areas (city centers, housing estates, industrial areas), big institutions and companies (municipalities, schools, universities, hospitals, shopping centers etc) [3]. This instrument of mobility management is appropriate to temporary events - trade fairs, concerts, sports matches - the organization of these events has a significant influence on the urban transport system and results often in paralysis of the city. Mobility plan solutions help to reduce the negative effects of temporary events organization.

Implementation of the mobility plans requires appropriate methodology, coordinate educational and informational activities as well as conscious participation of target groups (travellers, employees, employers, students, clients etc.). Very important issues are: monitoring of all activities, ability to drawn a conclusion from realization of activities and evaluation of their results.

The stages of the mobility plan implementation are the following [4]:

1. Definition of the mobility plan aims.

2. Determination of target area and target groups.

3. Analysis of the present situation (surveys about mobility behaviours and preferences, inventories of solutions and connections within PT, bikes, private transport and walking trips, analysis of parking situation etc.).

4. Definition of necessary activities to implementation (conceptual designs, marketing and educational activities etc.).

5. Implementation of proposed activities and solutions.

6. Evaluation of implemented activities.

As it has been mentioned, the mobility plan is a powerful instrument which can be used in the process of changing travellers' mobility behaviours. Two examples of the implemented mobility plans are presented below to prove it.

\section{An integrated mobility plan for the Cracow University of Technology (2005 - 2008)}

The first mobility plan in Poland was implemented by the Cracow University of Technology (Chair of Transport Systems) in the framework of the EU CIVITAS CARAVEL project [5]. It aimed at the change of the University employees' and students' mobility behaviours towards sustainable transport modes.

The University was affected by an increasing number of cars in the city - more employees and students used private cars to get to the University campuses which are located in different city areas. Alternative modes of transport are considered as less upmarket and insecure or simply did not exist.

The first phase of the mobility plan realization was an analysis of situation before the measure implementation (2005, 2006).
Mobility plan performers carried out surveys about employees' and students' travel behaviours and preferences as well as inventories concerning trip conditions to and from University campuses realized by public transport, bikechrbtys and cars. Results of the analysis allowed to formulate main activities within realization of the mobility plan.

In order to reach measure objectives, the following activities have been implemented [6] [7]:

\subsection{Carpooling system at Cracow University of Technology}

Carpooling is a more efficient way of private car usage - when more people use one vehicle during travelling to work, learning or leisure places, thereby economizing on fuel and reducing parking needs. The carpooling system called "Let's drive together" ("Jedzmy razem") has been implemented. This system is directed to employees and students and it helps them to contact each other and find a driver or passenger. Exchange of information is done by a special website "Let's drive together".

\subsection{New information website www.info- komunikacja.one.pl with data concerning sustainable mobility means}

The new information website "Info.Komunikacja" was established in order to provide information about public transport modes (bus and tram connections, schedules, ticket prices etc.), bikes (bike paths map, location of bike racks, bike rentals in Krakow etc.) and carpooling system (information concerning carpooling website, benefits from travelling in carpooling etc.). Employees and students could also use the travel planner, which enable them to precise plan of trips by public transport or car. After determination of a transport means, origin and destination places, the user gets trip route printed in the map and the travel time.

\subsection{Mobility Consultant post at the University}

A mobility consultant is a person who gives employees and students advice and information about travelling, and has influence on mobility behaviours. A mobility consultant gives information concerning bus, tram, rail and air transport connections and tariffs, car usage costs, bike paths in a city, carpooling system, development plans of city transport infrastructure etc.

\subsection{New bike policy}

Before implementation of the mobility plan there was insufficient amount of bike racks in the area of University campuses. As a result of the analysis of the biking situation 23 new bike racks have been newly installed and the amount of bike parking places has grown by 120. Also the information boards with bike racks location were set up in the of University campus area. 


\subsection{New car parking policy}

Within new car parking policy the cost of parking in the area of the University was doubled in 2007 in order to encourage parking users to use public transport and bikes and to reduce the parking places shortage. According to the declarations in survey $2008.5 \%$ of employees and $9 \%$ of extramural students have changed means of transport.

\subsection{Series of seminars and workshops}

During various seminars the sustainable mobility means and Caravel project were presented. An excellent idea was also a case study in the form of discussion with students concerning ideas of PT marketing actions. During workshops students also had to create concepts of mobility plans, goods distribution, demand responsive transport (a form of bus transport with flexible routing and scheduling, operating between pick-up and drop-off locations according to passengers needs).

\subsection{Marketing actions for promotion of sustainable transport modes}

In the mobility plan framework many marketing actions were realized, e.tg. brochures, leaflets, papers, posters and happenings - where the use of bikes, public transport and carpooling system was promoted. Fig. 1. presents one of these happenings - bike happening. It was a very successful action. During this event "The Book of University Bikers" was established as a base of people who travel by bike to the University and in their free time. At the same occasion, students could have their bikes inspected at free bike maintenance points and could get prizes in competitions. To avoid burglary the police marked the bicycles. It is worth mentioning that rector of the University also participated in the Ceremonial Bike Rides.

In 2008, thanks to the mobility plan activities, the share of one-person car trips to the University campuses decreased: - staff:

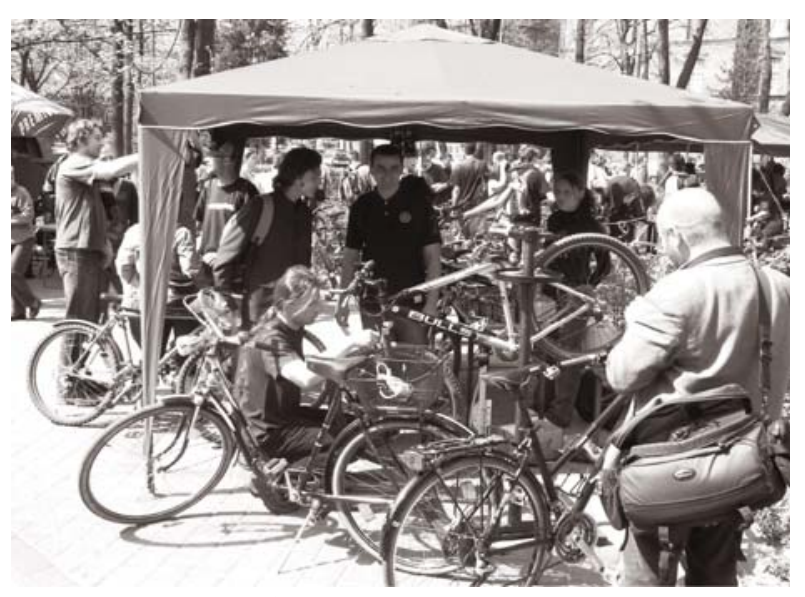

Fig. 1 Bike happening, April, 2007 from $45 \%$ to $41 \%$ and extramural students: from $50 \%$ to $30 \%$. It can be explained as a change from car trips (as a driver) to carpooling trips. The share of carpooling trips increased - staff: from $1 \%$ to $5 \%$, full-time students: from $0 \%$ do $7 \%$, and extramural students: from $1 \%$ to $17 \%$. Due to the increase in carpooling trips the need for parking at the University area was reduced. The number of staff travelling to the University by bikes was doubled [4].

\section{Integrated mobility actions for the San Martino Hospital in Genoa (2005-2008)}

The measure called "Integrated mobility actions for the San Martino Hospital in Genoa" is another successful mobility plan implemented within the EU CIVITAS CARAVEL project.

San Martino Hospital in Genoa is one of the biggest in Italy. More than 4.500 employees work in this hospital that covers more than $30.000 \mathrm{~m}^{2}$ with an internal road network of about $20 \mathrm{~km}$. It is located along one of the main street connecting the eastern part of the city and the centre, where the traffic flow in the morning peak hour is about 4.000 vehicles. Every day the hospital generates and attracts a large number of employees, patients, visitors and medical students. Moreover, due to the big pressure of vehicles on the area, the problem of lack of parking places is relevant [8].

An objective of the mobility plan for the hospital was to regulate all the public and private traffic generated/attracted by the hospital and by the surrounding areas in a more efficient way.

In order to achieve the objective following activities were implemented:

- Development of The Home Work Trip Plan (HWTP) for the hospital staff with a particular focus on the testing of a carpooling system.

- Establishment of the Infomobility Platform for employees and visitors with data about traffic and mobility in the city. The Infomobility Platform allows users to obtain real time transport information from www.mobilitypoint.it and to use the carpooling system website. Two kiosks with the access to the internet

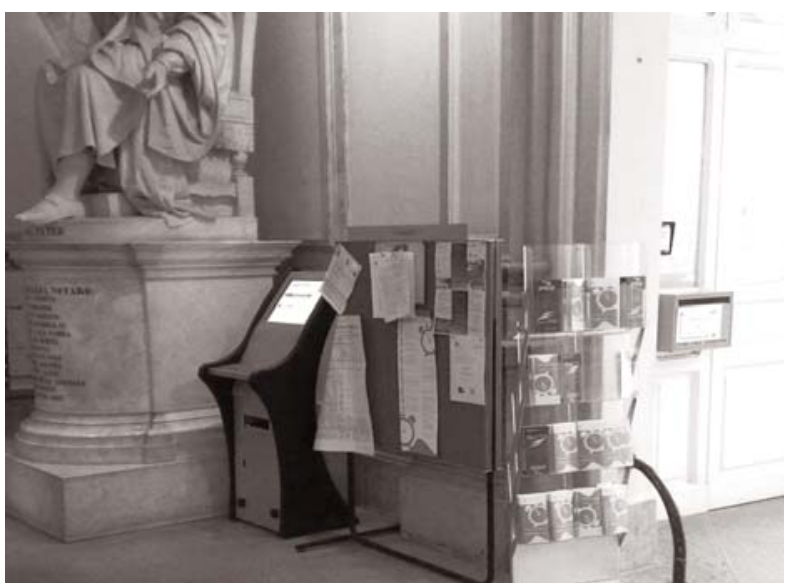

Fig. 2 One of the two kiosks with access to the Infomobility Platform 
and to the Infomobility Platform were installed in crucial locations inside the hospital.

- Increase of bus connections to the several departments inside the hospital.

- Extension of the public transport system (additional bus lines) inside of the hospital area for people coming early in the morning and late in the evening.

- Use of electric vehicles for goods distribution inside the hospital area.

- Dissemination of the mobility plan and sustainable mobility modes through: training, workshop, announcements on the notice boards inside hospital buildings, in the intranet and special bus (Infomobility Bus) parked outside the hospital days before the

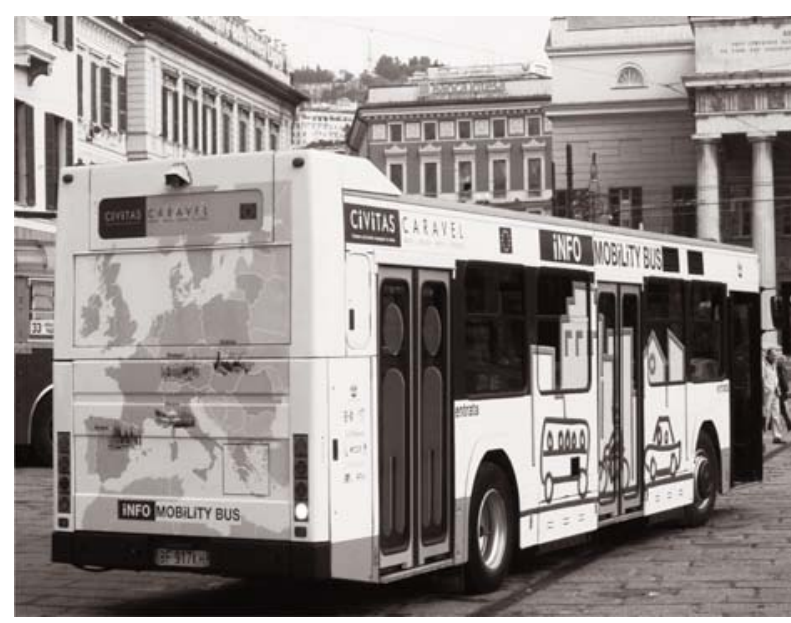

Fig. 3 Infomobility Bus [9] workshop. An Infomobility Bus is a kind of mobility point where one can find information about sustainable mobility means as well as place where $\mathrm{s} / \mathrm{he}$ can be given suggestions and ideas concerning the city transport organization [9].

Implementation of the mobility plan for the San Martino hospital allowed to obtain the following results (2008) [10]:

- The traffic flows in the street nearby the hospital decreased (in the west direction, in morning peak hours by $31 \%$ ).

- The share of car trips to the hospital decreased from $42 \%$ to $39 \%$.

- The share of walking trips increased from $5.5 \%$ do $11.5 \%$.

\section{Conclusion}

The change of travellers' behaviours is a very difficult process and its effects are usually not noticeable right after the implementation of appropriate instruments. But it is possible to meet traveller's mobility needs and to encourage them to travel in a more sustainable way as it was presented above. Activities realized within the mentioned mobility plans allowed to shape the mobility needs and attitudes of the target groups. These two examples have shown that very important issues are:

- Demonstration of more efficient and integrated modes of travelling.

- Influence on users mobility via development of bike and public transport infrastructure, improvement in services, information and consulting.

- Promotion of the sustainable transport via marketing and educational actions.

\section{References}

[1] Definition and Categorisation of Mobility Management Measures. Materials of the MAX project: Successful Travel Awareness Campaigns and Mobility Management Strategies, 2007,www.epomm.org/docs/MAX_Defn_catgsn_MM_measures_Final.doc

[2] www.epomm.org - European Platform on Mobility Management

[3] www.mobilitymanagement.be - Toolbox for Mobility Management Measures in Companies

[4] NOSAL, K.: Integrated Mobility Management, In proc. of conference Innowacyjne rozwiazania transportowe - doswiadczenia z realizacji projektu CIVITAS CARAVEL, Krakow, 2009

[5] www.civitas-initiative.org - CIVITAS - Cleaner and Better Transport in Cities

[6] NOSAL, K.: An Integrated Mobility Plan for the Cracow University of Technology, Proc. of conference Wspomaganie decyzji w projektowaniu i zarządzaniu transportem, SITK, Poznan, 2007

[7] NOSAL, K.: An Integrated Mobility Plan for the Cracow University of Technology, Proc. of: I International Interdisciplinary Technical Conference of Young Scientists, Poznan, 2008

[8] Caravel Inception Report, 11.8: Integrated mobility actions for the San Martino Hospital, Genoa 2005

[9] PIREDDU, P.: Mobility Marketing \& Mobility Forum, the experience of Genoa, Proc. of conference CIVITAS CARAVEL Summer University Burgos, Burgos, 2007

[10] Caravel evaluation report, 11.8: Integrated mobility actions for the San Martino Hospital, Genoa, 2008. 